Article

\title{
Perspectives on Consumer Habits with Domestic Refrigerators and Its Consequences for Energy Consumption: Case of Study in Guanajuato, Mexico
}

\author{
Juan M. Belman-Flores, Diana Pardo-Cely, Francisco Elizalde-Blancas, Armando Gallegos-Muñoz, \\ Vicente Pérez-García * and Miguel A. Gómez-Martínez \\ Engineering Division, Campus Irapuato-Salamanca, University of Guanajuato, Salamanca C.P. 36885, Mexico; \\ jfbelman@ugto.mx (J.M.B.-F.); dianapardocely@gmail.com (D.P.-C.); franciscoeb@ugto.mx (F.E.-B.); \\ gallegos@ugto.mx (A.G.-M.); gomezma@ugto.mx (M.A.G.-M.) \\ * Correspondence: v.perez@ugto.mx; Tel.: +52-464-647-9940
}

Received: 23 January 2019; Accepted: 25 February 2019; Published: 5 March 2019

\begin{abstract}
This work presents the main behaviors shown in the habits of consumers of domestic refrigerators, which influences the energy consumption of this appliance. This study is based on a series of surveys answered by 200 consumers from four cities in the State of Guanajuato, Mexico. The questions were arranged with the aim of evaluating the general characteristics and usage habits such as refrigerator age, door opening frequency, damper position, load of food supplies, external and internal cleaning habits, and nearby heat sources, among other things. The randomly interviewed consumers were individuals between 20 and 60 years of age, who were interviewed using handmade surveys by experts in the field of refrigeration. In some cases, photographic evidence was gathered from the consumers' refrigerators to represent the typical usage habits. In general, the results show that better usage habits are necessary from an energy point of view. Most consumers agree with adopting best practices for using their refrigerator.
\end{abstract}

Keywords: domestic refrigerator; consumer habits; energy consumption; good practices; surveys

\section{Introduction}

From early civilizations to present time, the need for preserving a space with a lower temperature than that from the environment, in relation to the handling and preservation of food, has been, and will continue to be a fundamental part of life. Thus, the refrigerator is one of the appliances most widely made because of its essential part in homes. Nowadays, domestic refrigeration based on vapor compression technology represents one of the major energy consumers in any home. This technology (air conditioning systems, refrigerators, among others, based on vapor compression) represents about $17 \%$ of the energy demand around the world [1]. Moreover, in 2009, approximately 80 million domestic refrigerators were produced [2]. Currently, around 1.5 trillion domestic refrigerators are in service worldwide [1]. These numbers are quickly changing due to the increase in consumers and the need for this type of appliances to preserve and to handle food.

In Mexico, the domestic sector demands the $26 \%$ of the national energy consumption, according to the Fideicommissum for the Energy Saving. Thirty percent of this corresponds to the energy consumption of the refrigerator, which is the second appliance with the most energy consumption in homes [3]. Moreover, in Mexico, $80 \%$ of homes own at least one refrigerator, which represents more than 23 million in service.

For the last few years, significant efforts have been made to improve the energy efficiency in domestic appliances. Some methods like energy consumption labelling consider energy efficiency as a 
guide for the search of energy improvements [4,5]. Coupled with this, a variety of mechanisms can increase the energy efficiency in a refrigerator and researchers are widely studying them; among the most relevant mechanism to mention include: improvements in the design of the main components (e.g., compressor and heat exchangers), adequate thermal insulation, application of the regulations, and analysis of the thermal behaviors at the compartments, among other things [6].

Without forgetting that currently there are drop-in replacements of Hydrofluorocarbons (HFCs), by low Global Warming Potential (GWP), refrigerants, in the Kyoto Protocol and recently in the Kigali agreement, there is the task to reduce the use of refrigerants with high GWP. Moreover, in the EU Regulation No. 517/2014 in domestic refrigerators and freezers, employing HFCs was forbidden with 150 or more as GWP [7]. In this sense, in the literature there are several papers where the use of Hydrocarbons, HCs, Hydrofluoroolefins (HFOs), and natural refrigerants in vapor compression refrigeration systems are focused on domestic refrigerators and freezers [8-12]. In fact, HCs are the most recommended [13]. However, despite the main problem with these refrigerants being their high flammability, they are now used in new domestic refrigerators in Europe. Nonetheless, due to being classified as A3 refrigerants, HCs are forbidden in Japan and USA.

On the other hand, currently in Mexico, the use of HFCs and Hydroclorofluorocarbons (HCFCs), is not forbidden yet. For this reason, in the development of this paper, the refrigerant that is present in homes is R134a.

In relation to the improvement of domestic refrigerators, it is clear that a reduction in the energy consumption of this appliance can cause a greater competitiveness for the maker. Moreover, it reduces the environmental impact caused by this appliance, and of course, a benefit for the consumers' savings [6]. On the other hand, factors like room temperature and relative humidity considerably affect the energy consumption of a domestic refrigerator [14,15] and they also affect the refrigerant type and charge used in the refrigerator [16]. Nevertheless, other factors like: door opening frequency, position of the damper, quantity of food, and compartments cleaning, among other things, depend on the consumers' habits, which play an important role in the cold chain and the adequate preservation of the food. Therefore, the consumer plays the main role in, and is responsible for the energy and thermal behavior in a refrigerator. In the literature, works that comprise the study of some of these factors with a statistic focus based on surveys are available. For example, Janjic et al. [17] studied the conditions under which the food is exposed inside the refrigerators such as temperature, cleanliness, and storage practices. The authors concluded that around half of the participants in the survey have inadequate food storage practices in their refrigerators. Moreover, the inner temperature of the refrigerator was considerably higher in comparison with the temperature recommended by the manufacturer. Geppert and Stammiger [18] evaluated consumer behavior concerning refrigerator usage and the main characteristics of these appliances. They analyzed room temperature conditions, compartment inner temperature, and the sources of heat near the refrigerator; all aspects that influence the performance of this appliance. Based on the results, the authors described a series of recommendations about energy efficiency, and with this, they concluded that the information specifically directed to consumers on this topic is scarce. Further in the reading, the authors extended their study to experimentally evaluate some of the operational factors that reflect the daily use of refrigerators such as room temperature, damper position, and the thermal load influenced by the food quantity. They concluded that the energy consumption was very sensitive to the room temperature and to a lesser extent, the refrigerator inner temperature and the thermal load [19]. Hasanuzzaman et al. [20] evaluated the usage habits in refrigerators such as the damper position and the thermal load, in addition to the room temperature and its influence on heat transfer, and the refrigerator's energy consumption. The authors confirmed that the room temperature and the thermal load represented a major impact on the heat transfer and the energy consumption. On the other hand, James et al. [21] gathered diverse studies performed globally that analyzed factors such as frequency with which doors were opened, cleanliness, food handling and storage, and the age of the refrigerator. The above was with the aim of analyzing the 
thermal behavior of the refrigerator and the cleanliness of the food in relation to their impact on consumer health.

According to the literature reviewed, it is necessary to explore in greater depth the role played by the consumer in the use of the refrigerator to analyze the impact on energy consumption and therefore propose a better use of the energy in this type of household appliances. Thus, this study analyzes diverse factors that influence the energy behavior of a domestic refrigerator. This work is based on the implementation of a series of surveys that were conducted specifically among consumers that live in cities of the State of Guanajuato, Mexico. In addition, the analysis and the results of this study contribute to providing more information about the usage habits of consumers and their relationship with food handling.

\section{Material and Methods}

The results presented in this study are based on a series of surveys conducted among consumers in cities of the State of Guanajuato, Mexico. The economic activities are different for each city in the state. In addition, consumers from different socioeconomic classes were selected for this survey with the aim of having a more representative sample from the central area of the country. Each of the participants were informed about the aim of the study, and with their prior consent, interviewed. At the end of the interview, photographic evidence was gathered from the inner compartments and exterior of the participants' refrigerator. The survey was performed among relatives, friends, and neighbors, all of them adults, and in different homes with different numbers of family members. Some interviews were also conducted among small homemade-cooking businesses, known as "cocinas económicas". These are typical places in Mexico where consumers buy homemade takeout food. The surveyor registered the answers on paper and by hand.

\subsection{Data Colletion}

With the aim of having results that reflect to a greater extent the behavior of the usage habits of domestic consumers' refrigerators, 200 surveys were conducted with participants from four cities in the State of Guanajuato and with different socioeconomic levels. The questions were prepared with the aim of demonstrating the energy behavior due to the usage habits of the consumers, and they were conducted by four expert investigators in the field of refrigeration. The questionnaire had 20 questions (see Appendix A), some of them with multiple-choice answers to complement more the main topic. Among the topics of interest and according to the objective of this study the participants were asked: about their refrigerator brand, the time the consumers owned the refrigerator (age), number of members in the family and who used the refrigerator, sources of heat near the refrigerator, (e.g., windows, stove, microwave oven, television), load of food in the compartments (very full, full, regular, mostly empty), number of times the refrigerator doors were opened, and inner and outer cleanliness, among other things. Finally, photographs were taken from those refrigerators showing the most inadequate usage habits. Some of them are presented in this study for illustrative purposes.

\subsection{Statistical Analysis}

The survey was conducted for 2 months, from May to June 2018 (temperate season with maximum temperature and relative humidity conditions of $27^{\circ} \mathrm{C}$ and $40 \%$, respectively), and once all the information was gathered, they were analyzed using Excel as a spreadsheet tool. In such manner, the tool facilitated creating graphics that reflected the behaviors of the usage habits of the consumers and allowed the analysis of the statistical significance ( $p$-value) for the quantitative questions (How long have you had your refrigerator?; How often do you open the refrigerator per day?; and How often do you clean your refrigerator?), as are shown in the next sections. This was with the objective of capturing trends regarding refrigerator energy consumption. Among the graphics shown in this paper, bar charts are presented to compare different values and categories. Additionally, pie charts were used to represent percentages and categories proportions. 


\section{Results and Discussion}

Knowing and quantifying the usage habits of refrigerators in Mexican homes, especially those in the State of Guanajuato, make it possible to project the use given to this appliance and the possible impact on energy consumption. This section highlights the main results of this study.

\subsection{Respondents}

The information gathered from the interviewed consumers was divided into: gender, age, and the number of people that commonly used the refrigerator. Two-hundred surveys were performed, and from these, $81 \%$ corresponded to women and $19 \%$ to men. These numbers highlight that, in this region of the country, it is women who generally participate in household activities and who provided most of the information gathered in this study. Regarding the age of the interviewed consumers, they are presented in groupings ranging from 20 to more than 60 years old, as is shown in Figure 1. Dividing the participants ages in this manner helps to understand how much the usage habits with refrigerator have changed from one generation to the next. According to Figure 1, it is shown that half of the participants are relatively young consumers, and their age ranks from 20 to 40 years old. Additionally, Figure 2 shows the number of people inhabiting in the surveyed homes, and that commonly use the refrigerator. The data distribution shows that the higher frequency number of inhabitants is four, which is a typical nuclear family in this part of Mexico.

\section{Age range}

20-30 years old

- 31-40 years old

- 41-50 years old

51-60 years old

- more than 60 years old

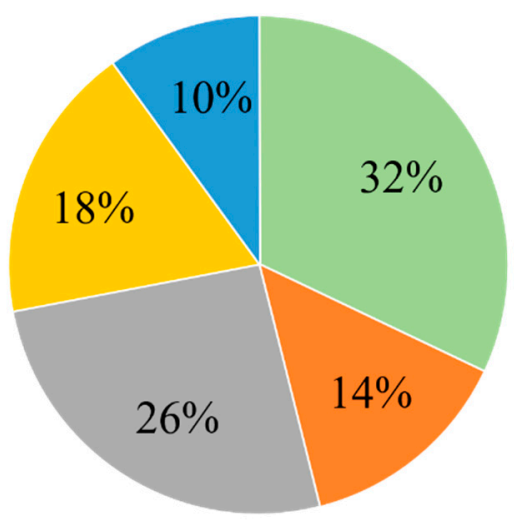

Figure 1. Age range of interviewed consumers.

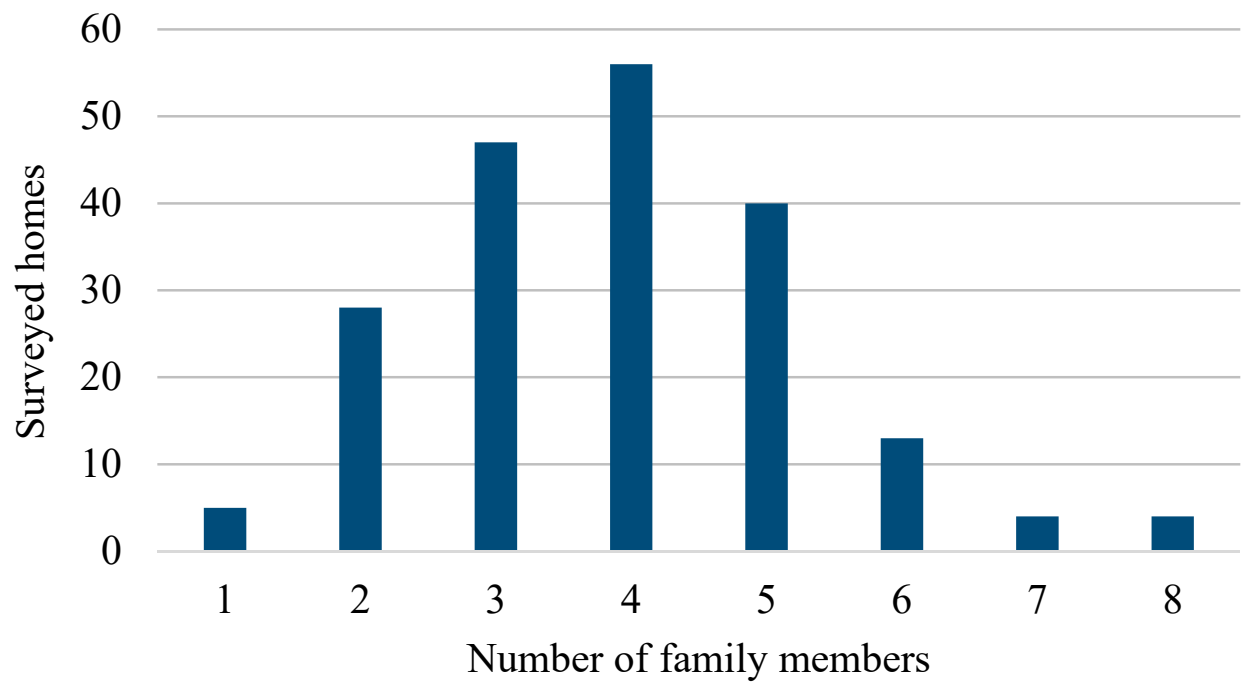

Figure 2. Number of family members in the surveyed homes. 


\subsection{Effect of Refrigerator Age}

From the 20 questions in the survey, seven are related to the refrigerator's general characteristics, like age and the amount of time the appliance has been in service since the consumer acquired it. The age and the design of the refrigerator play an important role in the energy consumption, as well as in the thermal behavior in the food compartments $[17,22]$. Modern refrigerators should be more efficient in comparison with older models; they should even be less harmful to the environment, when referring to the type of working fluid [16]. Table 1 shows the age of the refrigerators analyzed for this study.

Table 1. Age of the analyzed refrigerators.

\begin{tabular}{lccccc}
\hline & \multicolumn{5}{c}{ Age Range } \\
\hline Time (years) & $1-5$ & $6-10$ & $11-15$ & $16-20$ & More than 20 \\
Number of refrigerators & 88 & 62 & 24 & 14 & 12 \\
Percentage of refrigerators $(\%)$ & 44 & 31 & 12 & 7 & 6 \\
\hline
\end{tabular}

The table shows that $44 \%$ ( 88 refrigerators) of the consumers had a domestic refrigerator with modern technology and a labeling in accordance with the Mexican regulation NOM-015-ENER-2012 [23]. Additionally, the average age of the refrigerators was presented as eight years, with a confidence interval (CI 95\%: 7-9) and a statistical significance $p=0.026(p<$ 0.05). Studies on the application of energy policies for the replacement of old domestic refrigerators for newer and more efficient ones have shown interesting results for energy savings. It is suggested to replace a refrigerator that has more than 10 years of service. Hence, Table 1 shows that $75 \%$ (1-10 years of service) of consumers have adequate refrigerators from an energy efficiency point of view. Nevertheless, the usage habits can considerably affect this energy behavior. In Mexico, a campaign was implemented in 2001 to encourage the consumers to change their refrigerator for a newer and more efficient one. The results of this policy caused energy savings for $4.7 \mathrm{TWh} /$ year, which represents a 33\% of the total yearly energy consumption in the domestic sector [24]. Therefore, it was concluded that most of the participants' refrigerators are recent models (refrigerators with less than 10 years of service). The above mentioned is also related to this as a great part of the consumers were relatively young, around $46 \%$ of the consumers were between 20 and 40 years old (see Figure 1). Finally, it is worth noticing that a 13\% (more than 16 years in service) of the consumers should change their refrigerator for a new one.

\subsection{Refrigerator Design}

Another general characteristic related to the design of the refrigerator and important for the energy is the defrost system, this is, whether it produces frost or not. The above is simply focused on the comfort of the consumer and the energy consumption that represents a no-frost refrigerator (automatic defrost). According to the results of this study, $80 \%$ of the consumers have a no-frost refrigerator at home. This type of refrigerator does not generate frost because it has a thawing device in the freezer, which is generally an electric resistance that through radiation heat transfer removes the frost, which is a permeable coating of ice formed through the inner air humidity. It is worth mentioning that this type of refrigerator consumes more energy, but based on the survey results, consumers prefer them for comfort since it saves them the effort of defrosting it manually. Authors like Bansal et al. [25] estimated that the refrigerators with an automatic defrost system represent an increment in the energy consumption of around $17 \%$. It should be stressed in the present study that all the refrigerators over 16 years in service (see Table 1) present a manual defrosting, and therefore they should theoretically consume less energy. Nonetheless, because of the technology and the implications of their time in service, these refrigerators should be upgraded. According to some studies new refrigerators consume up to $60 \%$ less energy than older models for the same size and capacity after eight or more years of use [26]. 
On the other hand, the design of the magnetic seals in the refrigerator also plays an important role in the energy consumption. They are located on the edges of the refrigerator compartments doors to keep them close. Their usage and wear are caused by the frequency with which the doors are opened, and in many occasions, it is due to the low-quality material with which they are made. If the seals are in good conditions, the refrigerator doors must close hermetically, and they should not present heat gains through them. Seventy percent of the refrigerators reviewed in the survey did not show a visual wear in the seals, and therefore the consumers keep them in good conditions. Studies like the one from Afonso and Castro [27] concluded that an old and damaged seal produces an increase in the energy used by the compressor by $18.5 \%$, when comparing this to a refrigerator with new seals. Thus, the magnetic seals represent a maintenance opportunity that consumers must consider. Thirty percent of the refrigerators reviewed showed damage seals, which could imply a major energy consumption.

Another functional and general characteristic related to the design of the refrigerator is the dissipation of the heat absorbed from the food into the environment during the process of refrigeration. This dissipation is achieved in the condenser, which is a device of major importance in the design of the refrigerator because of its effect in its energy performance. Heat can be dissipated in two ways, the first is through natural convection of the air and the second is through forced convection, which is achieved using a fan. The latter increases the energy consumption in the refrigerator because of the fan. According to survey results in this study, Figure 3 depicts the typical designs of the condensers that the consumers have in their refrigerators. It is observed that 133 consumers have refrigerators in their homes with heat dissipation through natural convection using a wire-on-tube plate condenser. Nevertheless, the wire-on-tube plate condenser is more susceptible to accumulate dirt because of its location, which could affect the heat dissipation, and therefore the energy consumption. Forty-eight refrigerators dissipate the heat using a wire-on-tube coil condenser, this design of heat exchanger requires a ventilation device which slightly increases the energy consumption. Finally, 19 consumers have a refrigerator with a hot-wall condenser at home, which dissipates heat through air natural convection. It is important to mention that most consumers with a hot-wall condenser thought their refrigerator had a problem because of the hot lateral walls on their refrigerator.

\subsection{Damper Position}

The thermal condition for the storing of food depends on an appropriate distribution of the temperature inside the compartments of the refrigerator, without forgetting the appropriate design of the refrigeration system. Moreover, the thermal behavior is linked to the position of the damper (control element) which controls the air flow and the temperature. Depending on the damper scale, different positions can be selected. For example, some refrigerators are scaled with numbers from 1 to 9 ( 1 indicates high temperature, 5 medium, and 9 low), and some others are labeled as low, medium, and high. In any of the cases, the position represents a thermal condition for the refrigerator compartments. More sophisticated refrigerators have electronic controls (displays) where the consumer can set the temperature of the compartments. Only $2 \%$ of the refrigerators evaluated in the survey present a design of this type. In this study, the position of the damper was observed to predict the internal temperature of the refrigerator. Figure 4 shows these usage habits from the consumers. It was clearly observed that more than half of the consumers (113) keep their refrigerator in a medium position, this probably means that the food compartment keeps a temperature of around $3{ }^{\circ} \mathrm{C}$, while the freezer must have an average temperature of $-18^{\circ} \mathrm{C}$; refrigerators with a display are included here since their temperatures were like those mentioned before. These conditions are the typical calibration stablished by manufacturers in Mexico. Twenty-seven consumers adjust their damper in a low position, which represents a high thermal condition in the refrigerator compartments, $7.2^{\circ} \mathrm{C}$ in the food compartment and $-14.4^{\circ} \mathrm{C}$ in the freezer. The rest of the consumers (60) keep their refrigerators in a high position, which means that the refrigerator is in the coldest thermal condition, approximately $1.6^{\circ} \mathrm{C}$ in the food compartment and $-21^{\circ} \mathrm{C}$ in the freezer [16]. 


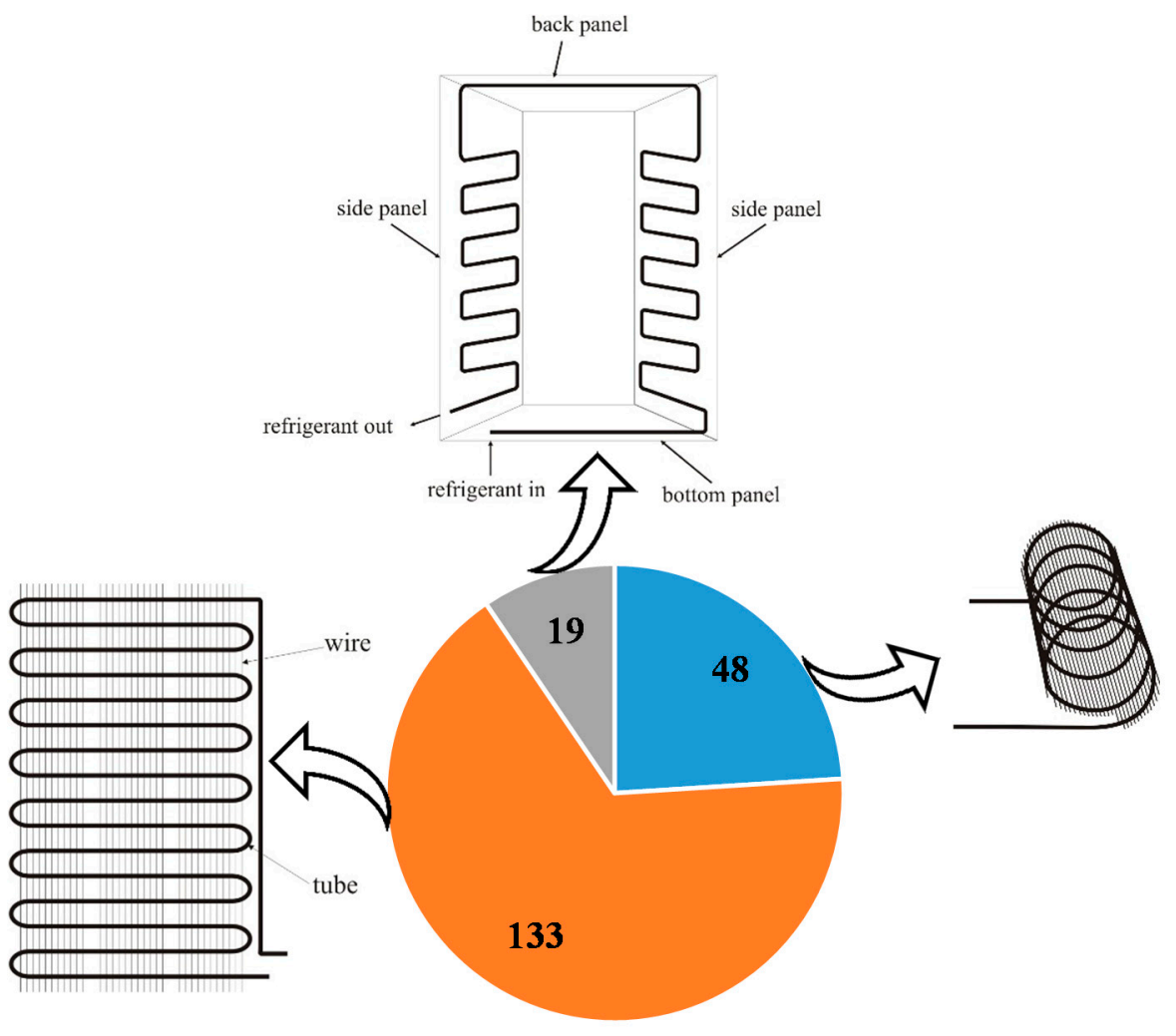

- wire-on-tube coil $\quad$ wire-on-tube plate $\quad$ hot-wall

Figure 3. Types of condensers in the studied refrigerators.

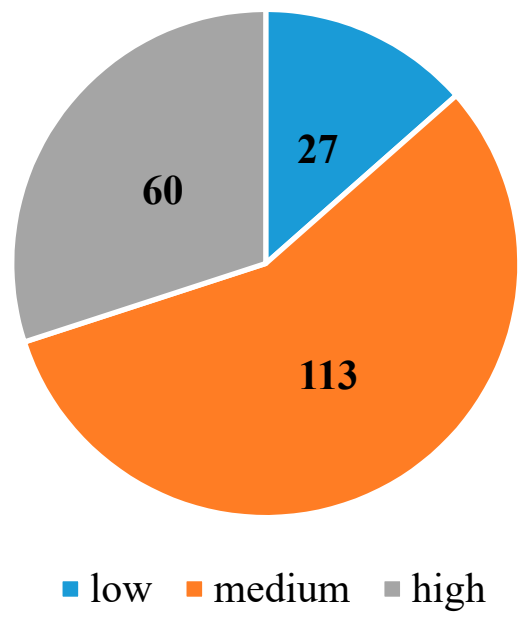

Figure 4. Damper positions in the analyzed refrigerators.

Most of the consumers do not know the temperature that the damper positions represent, and they prefer to keep the factory set position (position 5 or medium). The thermal conditions in the food compartment based on the damper position for this study are very similar to the ones presented by Geppert and Stamminger [18]. The authors reported that $66.3 \%$ of the users adjusted the temperature of the food compartment at $3{ }^{\circ} \mathrm{C}$, while the present study reports that a $56.5 \%$ of the consumers keep it at position $5\left(3{ }^{\circ} \mathrm{C}\right)$. In contrast, Derens-Bertheau et al. [28] found that the average temperature of food inside the refrigerator was $6.3^{\circ} \mathrm{C}$; one of the possible causes in the thermal difference is the calibration of the appliance and the location of the food inside the compartment. Lower temperatures in the compartments imply a major consumption of energy. For example, Saidur et al. [14] reported that the 
energy consumption increases around 7.8\% per each degree Celsius that the temperature is reduced in the freezer. While Geppert and Stamminger [19] concluded that the energy consumption increases with the decrease of the temperature, from 2 to $5 \%$ per each degree Celsius that the temperature is reduced in the food compartment. Similar results were found by Hasanuzzaman et al. [20] with increases of about $46 \mathrm{Wh}$ /day per each degree Celsius that the temperature decreases in the freezer. Hence, according to Figure 4, 30\% of the users (60 consumers) are likely to be in a condition of higher energy consumption due to the lower thermal conditions kept in the compartments of the refrigerator.

\subsection{Door Opening}

As is well known, the main purpose of the refrigerator is related to food preservation. Here the consumer plays an especial role in refrigerator management. The frequency with which the consumer opens the appliance doors to introduce or to withdraw food has an impact on the energy and thermal consumption of the refrigerator. Therefore, the design of the survey considered the number of doors each refrigerator has and the quantity of times these doors were opened. Based on the results from the survey, $35 \%$ of the consumers have single-door refrigerators at home. This type of refrigerator usually has the freezer integrated into the food compartment, and because of this, when the refrigerator door is open, the freezer is exposed to an unfavorable thermal condition due to the room temperature which is usually much higher than that of the freezer. The remaining $65 \%$ of consumers have two-door refrigerators, which have a physical separation between both the compartments, and they are only opened depending on the necessities of the consumers.

When a refrigerator door is opened, a heat gain is produced due to the heat transfer on the inner surfaces of the refrigerator and the humid air exchange. Furthermore, radiation heat is transferred from the surroundings to the refrigerator. This, along with an elongated time for the opening, causes the compressor to start more frequently to keep the refrigerator inner temperature. In this context, Rahman et al. [29] found a direct relation between the refrigerator temperature and the door opening frequency. Also, Saidur et al. [14] performed an experimental study in which their results showed a considerable influence on the energy consumption due to the door opening frequency, followed by the room temperature from the location of the refrigerator.

Figure 5 depicts the quantity of times that the consumer opened the food compartment door, including the single-door refrigerators. It should be noted that, for the consumer, this question was difficult, as they are not often aware of how frequently they open the refrigerator doors. In view of the above, the consumers were asked to count how often they open the refrigerator doors for a complete day. With these results, it was concluded that 78 consumers open the doors from 21 to 40 times a day. This represents $40 \%$ of the survey participants. While 54 consumers ( $27 \%$ of survey participants) open the doors from 41 to 60 times, with an average opening of 43 times a day and an estimate of the confidence interval of 95\% (CI: 40-46), representing a level of statistical significance $p=0.021$ $(p<0.05)$, which indicates that the door opening frequency is mostly concentrated in those ranges for the domestic refrigerator use. In current studies and related to these results, Brennan et al. [30] monitored domestic refrigerators to quantify the door opening frequency. The authors indicated that the most frequent times that doors were opened was 60. Figure 5 shows that nine consumers open doors as often as 100 times in a single day; most of these consumers are those who run a homemade food business, where food circulation is constant in the refrigerator. 


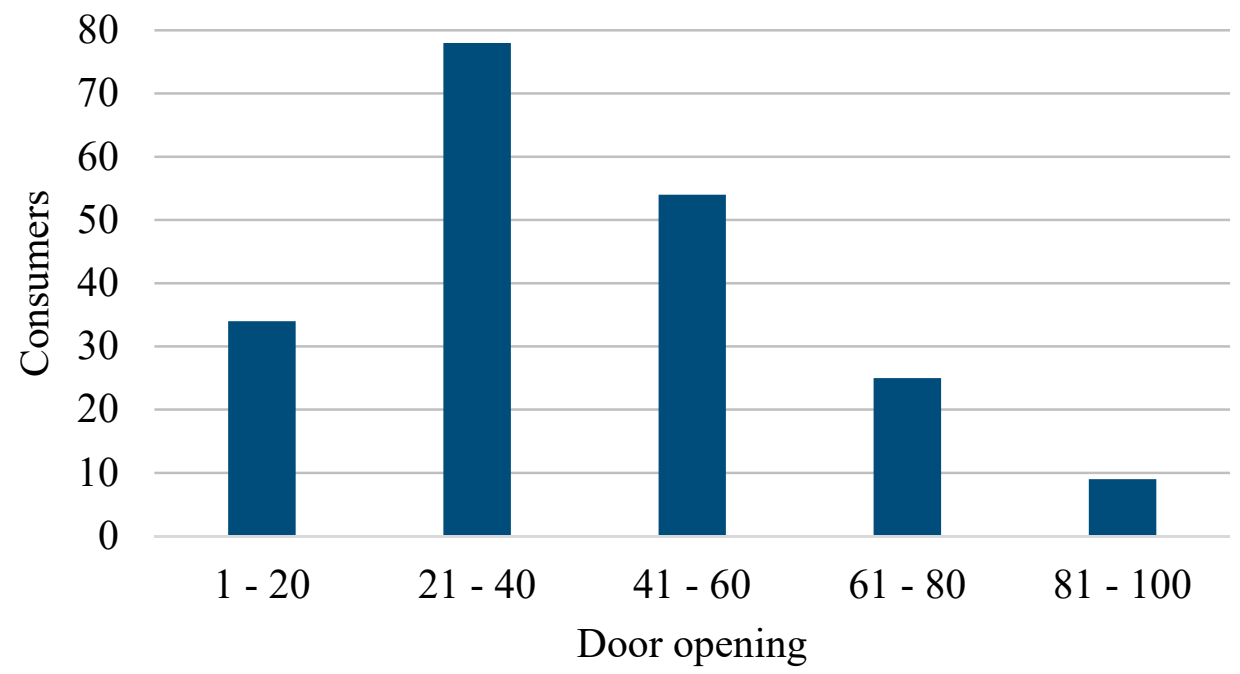

Figure 5. Door opening frequency ranges in the food compartments.

Regarding the times that the freezer door is opened, Figure 6 shows this habit behavior. Note that 152 consumers ( $76 \%$ of total) seldom open the freezer, between 0 to 8 times. It is clear that the food compartment door is open more frequently than the freezer door is, due to the type and amount of food that is stored in those spaces.

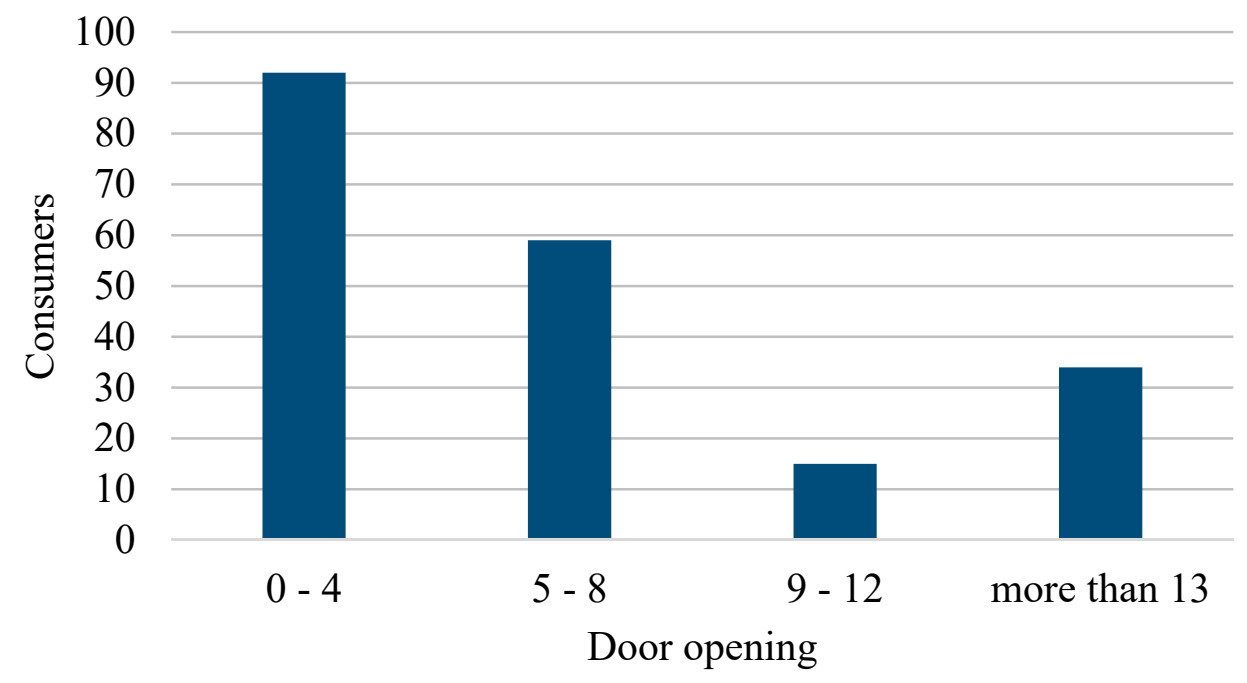

Figure 6. Door opening frequency ranges in the freezer compartment.

The different conditions for the door opening in a domestic refrigerator have been experimentally studied. For example, Khan and Afroz [31] demonstrated that the energy consumption is clearly increased up to $30 \%$, depending on the door opening frequency in comparison with a refrigerator that keeps its door close. The experimental results also show that the ON/OFF cycle of the compressor increased between 2 to 5 times due to the increase in the door opening frequency, which finally caused an increase in the energy consumption of the refrigeration system. Thus, the higher the door opening frequency is, the higher the times the compressor cycle is started; this implies an increase in the energy consumption. Most consumers expressed that they often open the refrigerator door inadvertently, or they simply forget something when circulating the food.

\subsection{Presence of Food Load}

The correct operation of the refrigerator is linked to an adequate distribution of the temperature and the air flow in the compartments. An appropriate temperature in the refrigerator could extend 
the food preservation [32], and it could also avoid the development of certain bacteria [33]. It was mentioned before that the thermal behavior is related to the energy consumption of the refrigerator. According to this, the consumer was asked about the practices he follows about the quantity of food stored in the refrigerator. Figure 7 shows the food load conditions in the consumers' refrigerator compartments. The load for the food compartment is indicated in blue and in gray for the freezer.

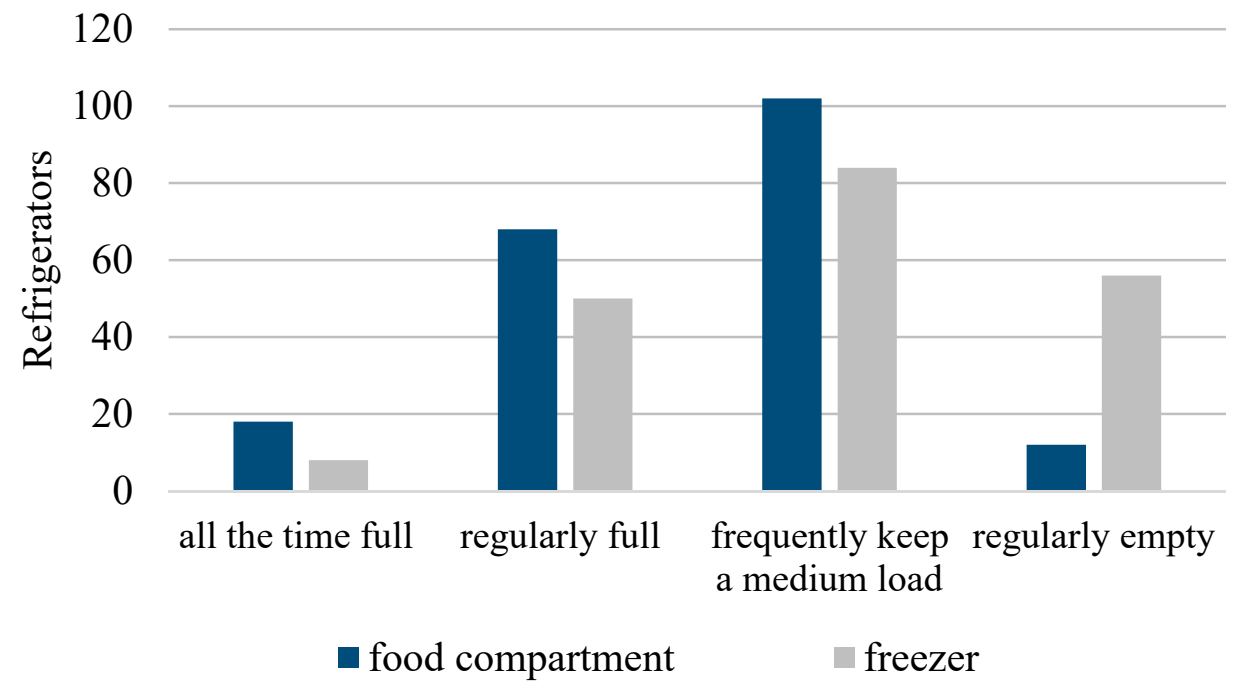

Figure 7. Food load in the refrigerator compartments.

Figure 7 shows that most of the consumers frequently keep a medium load in both compartments of their refrigerator, this represents $51 \%$ of the refrigerators evaluated for the food compartment and $42 \%$ for the freezer. It could be concluded that this is the most popular use for the refrigerator. A high number of consumers keep their refrigerator regularly full, i.e., they attempt to have a considerable amount of food in both refrigerator compartments. Other consumers keep their refrigerator full all the time; this means that a great quantity of food is always kept in the compartments. Finally, 12 consumers keep the food compartment regularly empty, and 56 keep the freezer empty. In this last habits category, the consumer has scarce perishable food in both compartments. To better illustrate the food load in the refrigerator, Figure 8 shows the aforementioned thermal load conditions. Under this premise is how the analyzed refrigerators were classified for this study.

The quantity of food and its distribution in the compartments could increase their inner temperature due to an inappropriate distribution of the air flow. This also depends on the refrigerator design when referring to the distribution of the air conducts. In the literature, some studies have analyzed the influence of the food load on the energy consumption in the refrigerator. One of the conclusions is that the ON/OFF cycles in the compressor are longer and more frequent in a refrigerator full of food than when it is empty. 


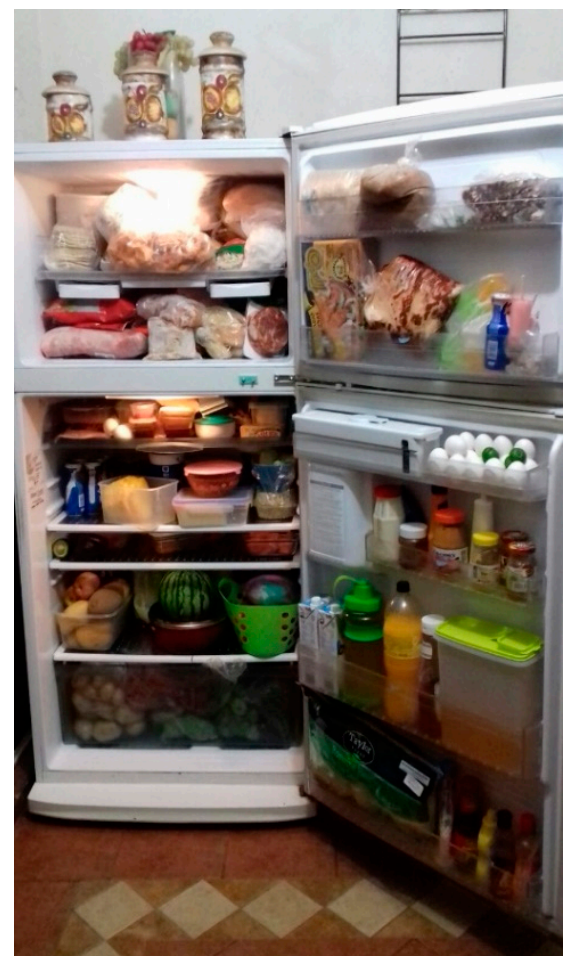

All the time full

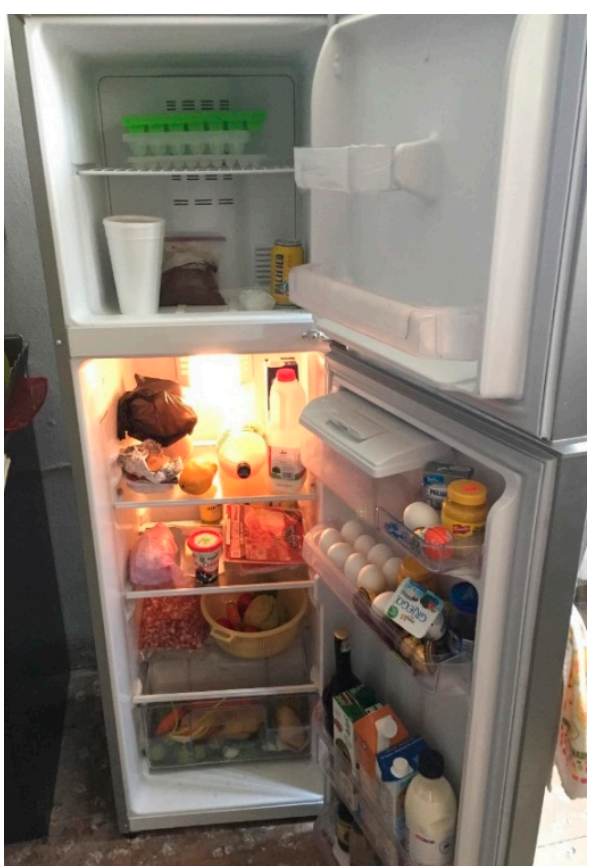

Frequently keep a medium load

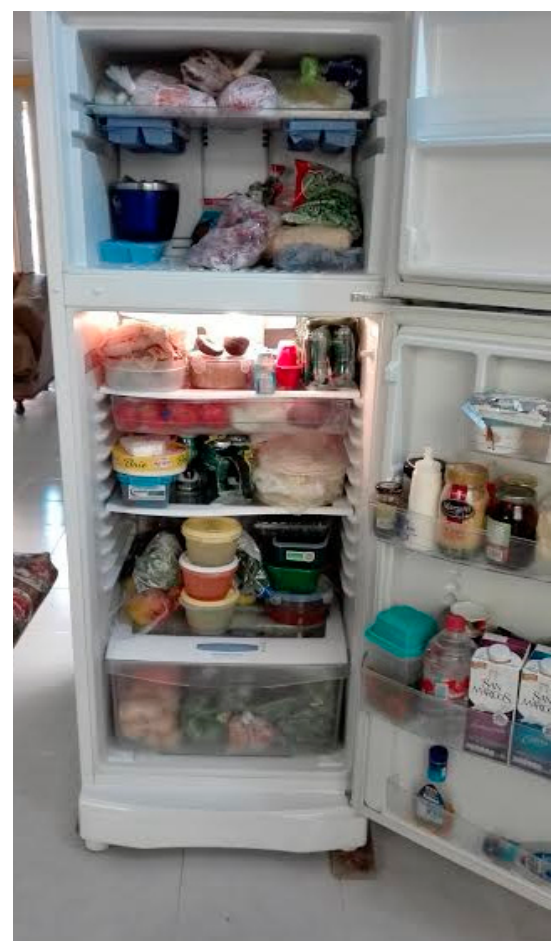

Regularly full

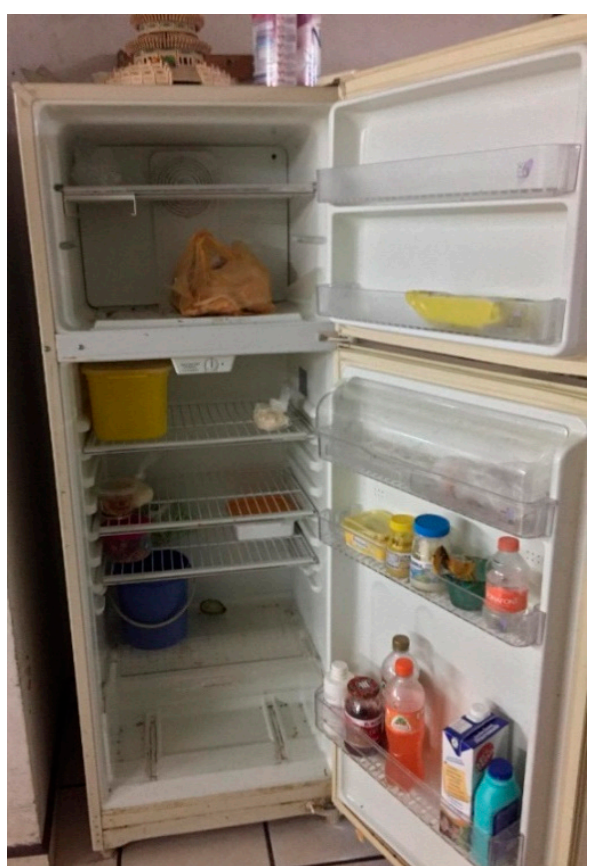

Regularly empty

Figure 8. Thermal load evidence in both the refrigerator compartments.

This happens because the temperature rate of change in the refrigerator is related to the thermal capacity of the food. Hasanuzzaman et al. [20] experimentally evaluated the influence of the food thermal load on the energy consumption, concluding that a significant impact on the energy consumption is observed. Geppert and Stamminger [19] concluded that an additional energy consumption occurs during the food cooling stage. Once the desired temperature is reached, the food 
load does not considerably affect the energy consumption. It is important to mention that these results may vary depending on the refrigerator design.

The inadequate usage habits of consumers with respect to the quantity of food in the compartments could cause a major energy consumption. According to Figure 8 and based on what was aforementioned, two situations are observed in which a major energy consumption is considered. The first corresponds to the consumers that keep their refrigerator always full, and the second, to those that have their refrigerator regularly empty. A better organization of the food enables a better distribution of the air flow, adequate temperatures, and less energy consumption. Additionally, new compartments designs are being produced with shorter spaces to access the food faster, and without the need to open the complete refrigerator door. This improves and keeps the thermal conditions, which manifest in a lesser energy consumption in the refrigerator.

\subsection{Refrigerator Cleaning}

It is well known that the refrigerator helps to extend the food preservation, and for this reason, one of the usage habits of the consumers is related to the optimal cleaning conditions. An inappropriate cleaning of the refrigerator compartments frequently causes the food to spoil, and moreover, it enables the development and growth of bacteria and odors [34]. As part of the design of the survey, a question was related to the cleaning frequency in the compartments and on the exterior of the refrigerator. Although the main objective of this study is not the refrigerator cleaning, and its effects in the development of certain bacteria, Figure 9 shows this maintenance habit to extend the information about the consumers' behavior. It was noticed that the consumers kept reasonable cleaning practices, in which the compartments were cleaned every two weeks, monthly, or at least biannually. Only four consumers $(2 \%)$ cleaned their refrigerator compartments once a year.

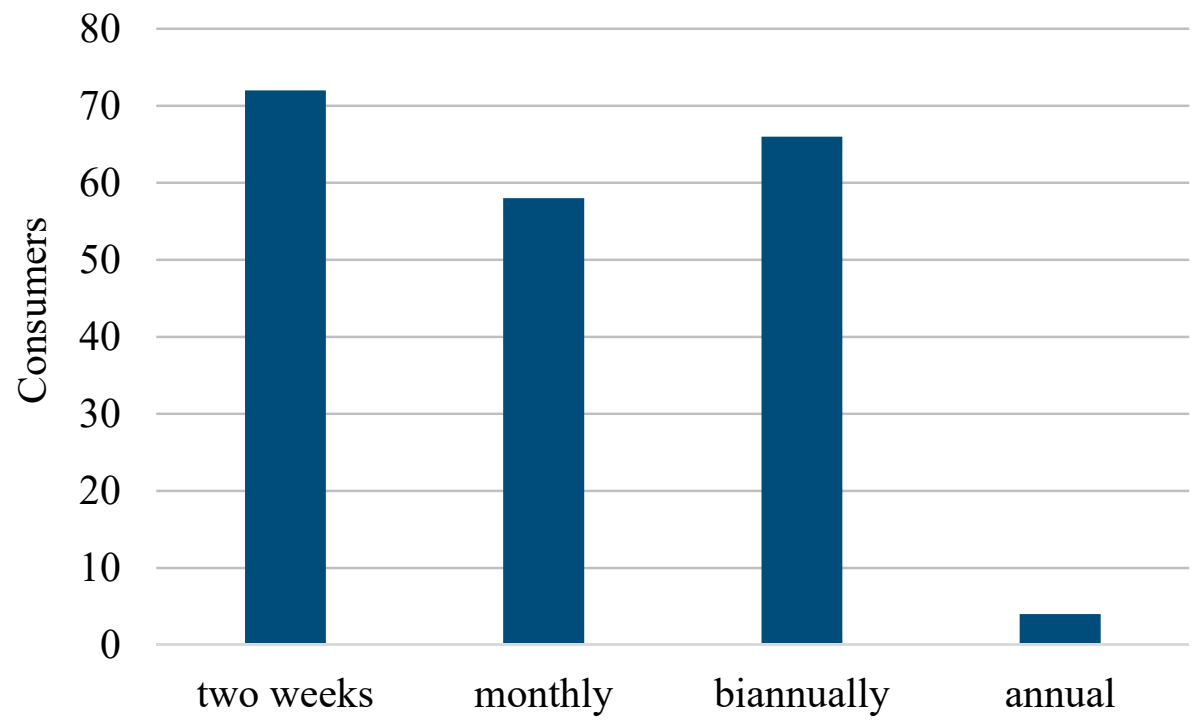

Figure 9. Cleaning frequency in the food compartments.

With respect to the external cleaning, this study highlights the cleaning related to the condenser. Most of the domestic refrigerators analyzed use a wire-on-tube condenser as heat exchanger to dissipate the absorbed heat during the food cooling process (see Figure 3). However, given the fact that a large number of the consumers did not have a cleaning habit for this device, and did not even know its function, the external dirt becomes excessive, mainly composed of dust, fluff, grease, etc. This caused an incorrect operation in all the vapor compression systems, and most refrigerators are based on this technology, since it limits the heat transfer into the environment [35]. For example, Hermes and Melo [36], through the development of a dynamic model, evaluated the effect of the condenser fouling, and they affirmed that this increases the energy consumption by $2 \%$. Belman-Flores [37] 
experimentally found a variation in the temperature of the refrigerator compartments when comparing a clean condenser with a dirty one. Figure 10 depicts a typical case of fouling found in most of the reviewed refrigerators.

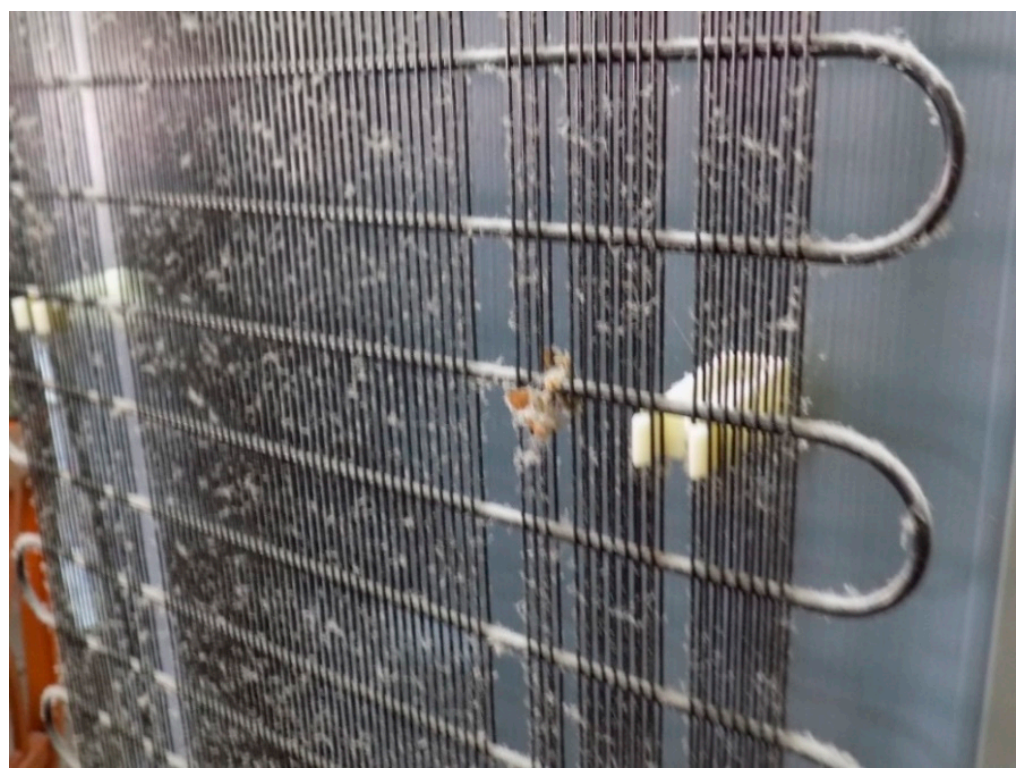

Figure 10. Typical fouling in a condenser.

Figure 11 shows the survey results regarding the condenser cleaning frequency. It was observed that 154 consumers never cleaned the condenser $(p<0.01)$, which causes an inadequate performance in the system, which was noticed in an increase in the energy consumption. Part of the reason for this lack of cleanliness is due to the position of the refrigerator in a particularly enclosed space and the little attention the consumer pays to the back of the appliance.

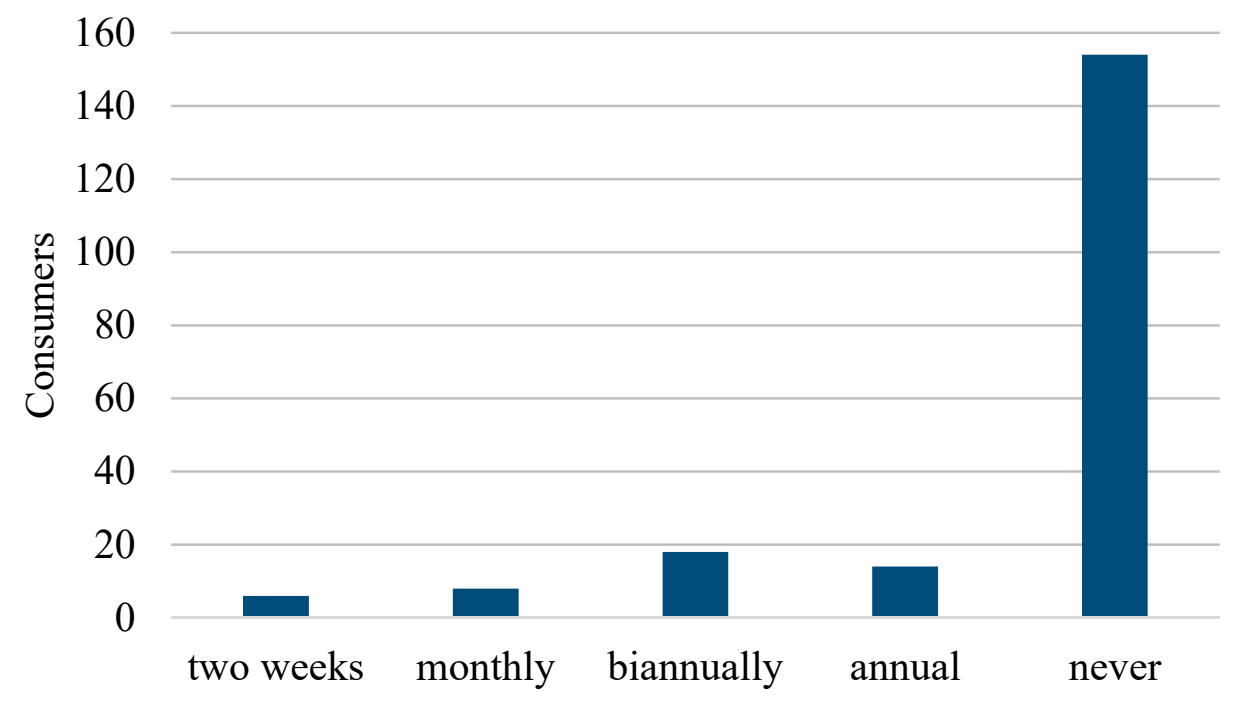

Figure 11. External cleaning of the refrigerator (condenser).

\subsection{Refrigerator Close to Heat Sources}

Having the refrigerator close to a heat source can affect the temperature in the compartments and increases the energy consumption. This increase is in a range of 0.9 a $1.3 \%$ as presented in the work of Lepthien [38]. While conducting the survey, Lepthien paid special attention to the refrigerator conditions and its location with respect to heat sources. For example, $23.5 \%$ of the consumers kept 
their refrigerator away from heat sources. This information is contrary to what other authors have reported; for example, Laguerre et al., [39] reported that 70\% of consumers have their refrigerators away from heat sources. While Geppert and Stamminger [18] reported that $34.2 \%$ of consumers keep their refrigerator near heat sources. In this study, $76.5 \%$ of the consumers have their refrigerator near a heat source. This difference in the results found by other authors could be explained by the architecture of the homes. In Mexico, housing constructions are built in a horizontal manner, and many homes have their kitchen area in front of a gardening area, where it generally has a lot of windows that allow the sunlight to have direct contact with the refrigerator. Moreover, inadequate spacing in kitchens causes consumers to have their refrigerator near heat sources like a stove or a microwave oven. According to the results in this study, Figure 12 shows the distribution of the main heat sources near the refrigerator. The most common heat source near the refrigerator is a microwave oven. The next heat source is when the refrigerator is directly exposed to sunlight through a window, which during several hours of the day represents a continuous heat source. Other consumers have the stove extremely close to the refrigerator, which is a heat source that provides a great quantity of energy to the refrigerator because of its use, whether the burners and/or the oven. Another common habit of the consumers was when they placed a television on top of the refrigerator. Finally, in some cases the consumer had more than one heat source near the refrigerator, which represented $9 \%$ of the consumers. Figure 13 depicts evidence of heat sources near the refrigerator. Notice those relevant cases where the consumer had three different nearby heat sources. These usage habits cause an incorrect performance in the refrigerator. Nevertheless, most of them are heat sources used for short periods of time, yet influence the refrigerator performance.

\subsection{Preferences in the Purchase of a Refrigerator}

Before acquiring a refrigerator, it is important to understand the needs of the family group. Thus, the consumers were asked about their decision standards when buying a refrigerator. Figure 14 shows the most popular decision standards followed by the consumers. The figure shows that $60(30 \%)$ of consumers made their decision to buy a refrigerator based on the energy savings concept, and the rest for other reasons shown in the figure. Energy saving is an important point to consider, as it is necessary to provide more information to the consumer on the importance of buying appliances with adequate energy efficiencies. In Mexico, energy efficiency awareness programs related to refrigerators have been disregarded. For example, campaigns encouraging the consumer to change their old refrigerator for a new one have completely stopped.

$\square$ window
$\square$ stove
$\square$ microwave oven
$\square$ television
$\square$ others

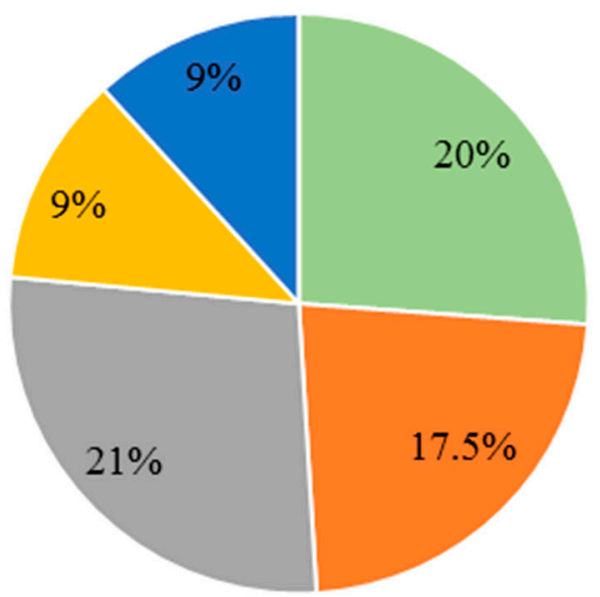

Figure 12. Typical heat sources near the refrigerator. 

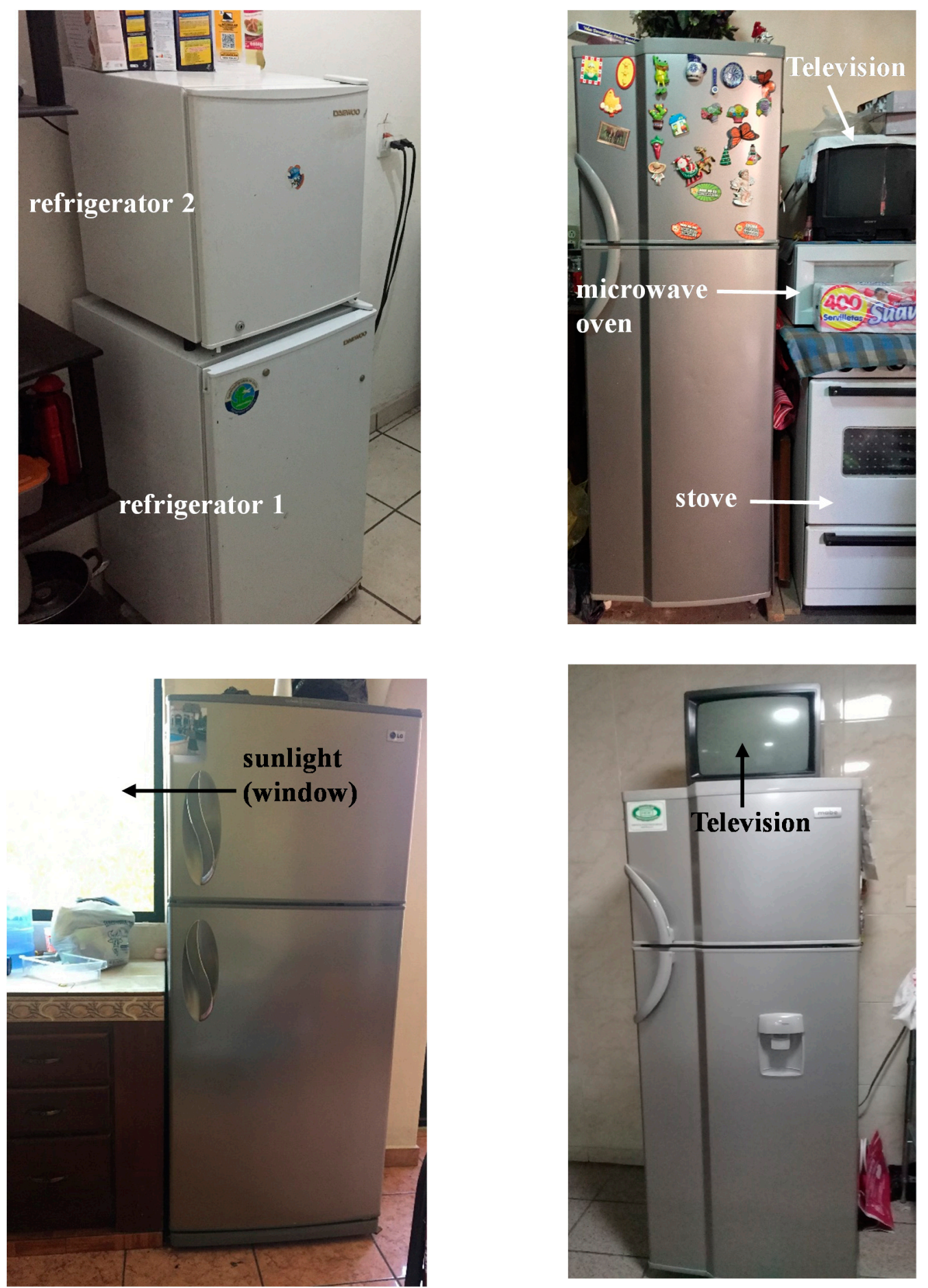

Figure 13. Typical examples of heat sources near the refrigerator. 


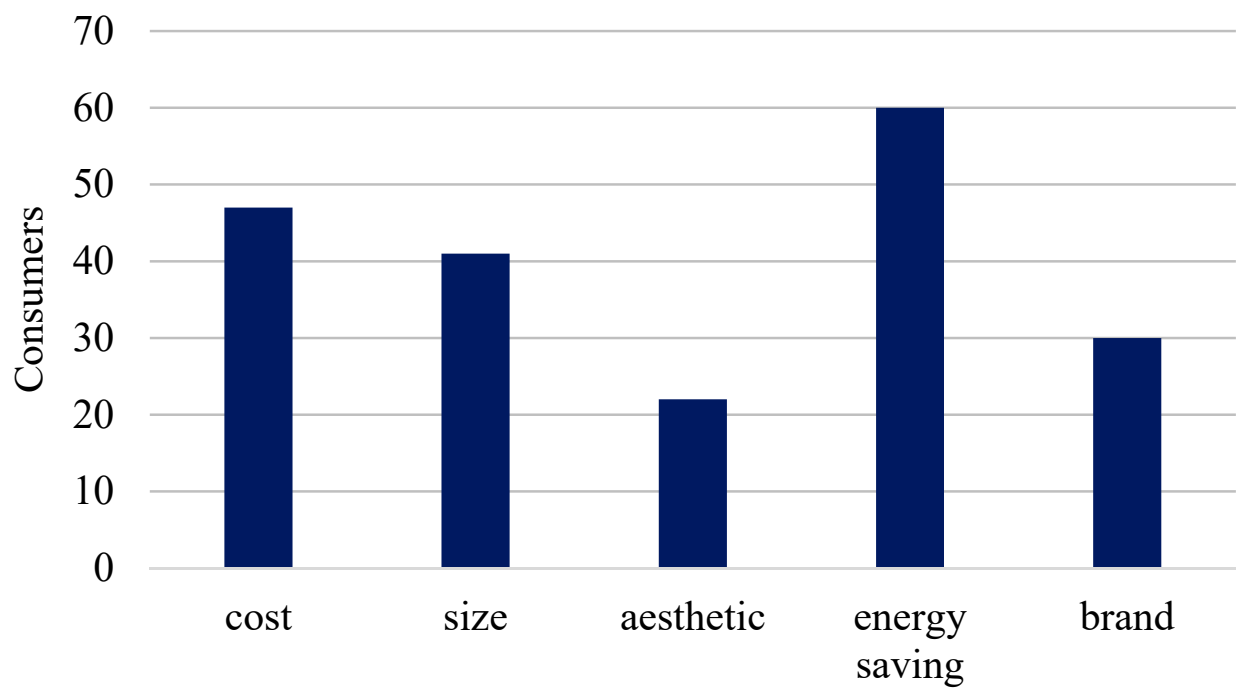

Figure 14. Consumers' decision standards for buying a domestic refrigerator.

Therefore, it was clear that for 60 consumers reducing energy consumption played a major role when deciding to acquire a refrigerator. The refrigerator cost also played a crucial role for the consumer, which frequently depended on the technology which was directly related to energy aspects. It is a little intriguing that size was not an important standard for the consumers when buying a refrigerator, because, based on the survey, around $45 \%$ of the consumers claim that their refrigerator was not adequate for their needs. The possible explanation is that the members of the nuclear family extended, or on the contrary, they diminished, and therefore, the size of the refrigerator became inappropriate with respect to their initial needs. This can influence energy consumption due to the aforementioned food load. The brand was another important aspect for the consumer according to the survey. Table 2 shows the refrigerator brand that consumers have at home. It was observed that the refrigerators produced by Mabe were the most popular, followed by Whirlpool, LG, and Daewoo, among other brands. It is important to highlight that Mabe has its main refrigerator factory located in the State of Guanajuato, which encourages a high consumption of domestic appliances in the region and this tendency is like the one reported by other authors on a national level [24].

Table 2. Most popular refrigerator brands in the surveyed homes.

\begin{tabular}{cc}
\hline Brand & Refrigerators \\
\hline Mabe & 64 \\
Whirlpool & 41 \\
LG & 22 \\
Daewoo & 16 \\
Samsung & 12 \\
Kenmore & 11 \\
Frigidaire & 10 \\
Koblenz & 8 \\
Singer & 8 \\
Supermatic & 8 \\
\hline
\end{tabular}

\subsection{Remarks}

The results shown in the previous sections clearly exemplify the main refrigerator usage habits of consumers. It is important to stress that the usage habits considerably influenced the refrigerator energy consumption. According to the results presented in this article, it is concluded that the consumers in this region of Mexico perform an adequate practice in some usage habits. However, for the ones remaining, a great percentage of consumers place their refrigerator near heat sources, which may cause 
the refrigerator to malfunction. Another inadequate habit is related to the position of the damper, which must be set by the consumer according to the food load or the required thermal condition in the compartments. Another point to highlight is that the consumer must be better informed when buying a refrigerator. The refrigerator must be adequate for the number of family members living at home and the quantity of food they handle. The lack of cleaning of the heat exchanger equipment, like the typical condenser in the evaluated refrigerators, is another of the habits that causes inadequate thermal conditions in the refrigerator compartments, and therefore inadequate energy consumption. Finally, the food load greatly affects the energy consumption in the refrigerator. However, according to the results in this paper, almost half of the consumers maintained their refrigerators with a proper thermal load.

Therefore, it is necessary to diffuse the most adequate usage habits for the refrigerator through the establishment of government or refrigerator manufacturer programs. With this, a sustainable appliance would be achieved/projected through its technology and its use. In this sense, it is expected that manufacturers also commit to the use of refrigerants with low global warming potential [16,40], as it has been pronounced in the Kigali Amendment, which came into effect as of January 2019 [41]. Finally, it is important to mention that the results presented in this paper may be different for consumers from other states in Mexico. Nevertheless, this study is a basis to deepen understanding of the usage habits, and with this, encourage a culture of adequate practices on the usage of refrigerators.

\section{Conclusions}

This article has presented the behaviors of the main domestic refrigerator usage habits of consumers and their influence on energy consumption. Among the main usage habits discussed in this study, based on a survey, were: the refrigerator age, door opening frequency, damper position, food load, external and internal cleaning, and the nearby sources of heat. The findings indicate that consumers have little knowledge on how refrigerator usage habits affect their appliance energy consumption. Inadequate behaviors were shown during the handling of the food, and this probably caused an increase in energy consumption. This type of study should provide recommendations through manufacturers, which should provide guidance to consumers on better usage practices for this appliance, either through user manuals or signage for use outside or inside the refrigerator. Additionally, dissemination actions could be implemented on energy savings in homes through radio or television campaigns by the federal government. Another possibility would be locally through social service by university students who campaign in homes about the habits surrounding the use and their effects on energy consumption. Most consumers agreed in receiving this kind of orientation and adopting proposals to upgrade their old refrigerators.

Finally, when attempting to achieve a decrease in refrigerator energy consumption and more efficient designs, it is important to know and understand more widely the behavior of the usage habits of consumers. Therefore, presenting the main results of this study is relevant.

Author Contributions: Conceptualization, J.M.B.-F. and D.P.-C.; methodology, F.E.-B. and A.G.-M.; resources, M.A.G.-M.; analysis of data, V.P.-G., J.M.B.-F. and D.P.-C. wrote the paper. All authors have read and approved the final manuscript.

Funding: This research received no external funding.

Acknowledgments: We acknowledge University of Guanajuato for their sponsorship in the realization of this work.

Conflicts of Interest: The authors declare no conflict of interest.

\section{Appendix A}

SURVEY (Common usage for the domestic refrigerator)

Refrigerator brand

How long have you had your refrigerator? age 
How many doors does the refrigerator have? One __ Two

How many family members have access to the refrigerator?

Three

Do you know what's the recommended temperature for the refrigerator compartments? No Yes Freezer Freshfood compartment

Does your refrigerator generate frost? (do you unplug your refrigerator to defrost it? Yes__ No_ How often do you clean your refrigerator?

Inside: Outside (front, doors): Outside (condenser):

Do you unplug your refrigerator to clean it in the inside? Yes No

Approximately, how often do you open the refrigerator a day? FF (fresh food compartment)__ FZ (freezer)

Do you ever store hot/warm food in the refrigerator? No __ Yes _ _ (How frequently?)

Do you defrost your frozen food in the food compartment? Yes No

Heat sources near the refrigerator

Window Stove___ Oven

Television

Others

How full do you keep your refrigerator regularly (thermal load)?

- Food compartment: Very full__ Full__ Regularly full__ Empty most of the time

-Freezer: Very full__Full__ Regularly full__ Empty most of the time

Do you consider the refrigerator size adequate for your needs? Yes_ No_

If you bought a refrigerator now, how would you make that decision? According to: Price___ Size___ Looks ___ Energy saving ___ Brand

How often do you acquire (buy) a refrigerator?

Surveyor:

Visual wear of the refrigerator seals

What's the damper position? Low Mechanical or digital

What type of condenser is in the refrigerator? Plate__ Espiral__ Hot wall_

Size of the refrigerator: Big Medium Small

General observations:

\section{References}

1. Coulomb, D.; Dupont, J.L.; Pichard, A. The role of refrigeration in the global economy. In 29th Informatory Note on Refrigeration Technologies; IIR document; International Institute of Refrigeration: Paris, France, 2015.

2. Seong, S. Experimental study of heat transfer characteristics for a refrigerator by using reverse heat loss method. Int. Commun. Heat Mass Transfer 2011, 38, 572-576.

3. Balance Nacional de Energía 2012, Secretaría de Energía; Dirección General de Planeación e Información Energéticas: México, 2013.

4. Vine, E.; Du Pont, P.; Waide, P. Evaluating the impact of appliance efficiency labeling programs and standards: Process, impact, and market transformation evaluations. Energy 2001, 26, 1041-1059. [CrossRef]

5. Bansal. Developing new test procedures for domestic refrigerators: Harmonization issues and future R\&D needs-A review. Int. J. Refrig. 2003, 26, 735-748.

6. Belman-Flores, J.M.; Barroso-Maldonado, J.M.; Rodríguez-Muñoz, A.P.; Camacho-Vázquez, G. Enhancements in domestic refrigeration, approaching a sustainable refrigerator-A review. Renew. Sustain. Energy Rev. 2015, 51, 955-968. [CrossRef]

7. The European Parliament and the Council. No. 517/2014 of the European Parliament and the council of 16 april 2014 on fluorinated greenhouse gases and repealing regulation (EC) No. 842/2006 text with EEA relevance. Off. J. Eur. Union I 2014, 150, 195-230.

8. Aprea, C.; Greco, A.; Maiorino, A.; Masselli, C. The drop-in of HFC134a with HFO1234ze in household refrigerator. Int. J. Therm. Sci. 2018, 127, 117-125. [CrossRef]

9. Navarro-Esbrí, J.; Mendoza-Miranda, J.M.; Mota-Babiloni, A.; Barragán-Cervera, A.; Belman-Flores, J.M. Experimental analysis of R1234yf as a drop-in replacement for R134a in a vapor compression system. Int. J. Refrig. 2013, 36, 870-880. 
10. Raghunantha Reddy, D.V.; Bhramar, P.; Govindarajulu, K. Hydrocarbon Refrigerant mixtures as an alternative to R134a in Domestic Refrigeration system: The state-of-the-art review. Int. J. Sci. Eng. Res. 2016, 7, 87-93.

11. Belman-Flores, J.M.; Rangel-Hernández, V.H.; Usón, S.; Rubio-Maya, C. Energy and exergy analysis of R1234yf as drop-in replacement for R134a in a domestic refrigeration system. Energy 2017, 132, 116-125. [CrossRef]

12. Kasaeian, A.; Hosseini, S.M.; Sheikhopour, M.; Mahian, O.; Yan, W.; Wongwises, S. Applications of eco-friendly refrigerants and nanorefrigerants: A review. Renew. Sustain. Energy Rev. 2018, 96, 91-99. [CrossRef]

13. Palm, B. Hydrocarbons as refrigerants in small heat pump and refrigeration systems-A revew. Int. J. Refrig. 2008, 31, 552-563. [CrossRef]

14. Saidur, R.; Masjuki, H.H.; Choudhury, I.A. Role of ambient temperature, door opening, thermostat setting position and their combined effect on refrigerator-Freezer energy consumption. Energy Convers. Manag. 2002, 43, 845-854. [CrossRef]

15. Ghadiri, F.; Rasti, M. The effect of selecting proper refrigeration cycle components on optimizing energy consumption of the household refrigerators. Appl. Therm. Eng. 2014, 67, 335-340. [CrossRef]

16. Belman-Flores, J.M.; Rodríguez-Muñoz, A.P.; Gutiérrez Pérez-Reguera, C.; Mota-Babiloni, A. Experimental study of R1234yf as a drop-In replacement for R134a in a domestic refrigerator. Int. J. Refrig. 2017, 81, 1-11. [CrossRef]

17. Janjic, J.; Katic, V.; Ivanovic, J.; Boskovic, M.; Starcevic, M.; Glamoclija, N.; Baltic, M.Z. Temperatures, cleanliness and food storage practices in domestic refrigerators in Serbia, Belgrade. Int. J. Consum. Stud. 2016, 40, 276-282. [CrossRef]

18. Geppert, J.; Stamminger, R. Do consumers act in a sustainable way using their refrigerator? The influence of consumer real life behavior on the energy consumption of cooling appliances. Int. J. Consum. Stud. 2010, 34, 219-227. [CrossRef]

19. Geppert, J.; Stamminger, R. Analysis of effecting factors on domestic refrigerator's energy consumption in use. Energy Convers. Manag. 2013, 76, 794-800. [CrossRef]

20. Hasanuzzaman, M.; Saidur, R.; Masjuki, H.H. Effects of operating variables on heat transfer and energy consumption of a household refrigerator-Freezer during closed door operation. Energy 2009, 34, 196-198. [CrossRef]

21. James, C.; Onarinde, B.A.; James, S.J. The use and performance of household refrigerators: A review. Compr. Rev. Food Sci. Food Saf. 2017, 19, 160-174. [CrossRef]

22. Hassan, H.F.; Dimassi, H.; El Amin, R. Survey and analysis of internal temperatures of Lebanese domestic refrigerators. Int. J. Refrig. 2015, 50, 165-171. [CrossRef]

23. Secretaría de Energía. Comisión Nacional para el Uso Eficiente de la Energía. Norma Oficial Mexicana NOM-015-ENER-2012, Eficiencia Energética de Refrigeradores y Congeladores Electrodomésticos. Límites, Métodos de Prueba y Etiquetado; Secretaría de Energía: Mexico City, Mexico, 2012. (In Spanish)

24. Arroyo-Cabañas, F.G.; Aguillón-Martínez, J.E.; Ambríz-García, J.J.; Canizal, G. Electric energy saving potential by substitution of domestic refrigerators in Mexico. Energy Policy 2009, 37, 4737-4742. [CrossRef]

25. Bansal, P.; Fothergill, D.; Fernandes, R. Thermal analysis of the defrost cycle in a domestic freezer. Int. J. Refrig. 2010, 33, 589-599. [CrossRef]

26. General Commission for the Efficient Use of Energy, Secretariat of Energy. 2014. Available online: https: / / www.gob.mx/conuee\#3548 (accessed on 18 July 2018).

27. Afonso, C.; Castro, M. Air infiltration in domestic refrigerators: The influence of the magnetic seals conservation. Int. J. Refrig. 2010, 33, 856-867. [CrossRef]

28. Derens-Bertheau, E.; Osswald, V.; Laguerre, O.; Alvarez, G. Cold chain of filled food in France. Int. J. Refrig. 2015, 52, 161-167. [CrossRef]

29. Rahman, S.; Sidik, N.M.; Hassan, M.H.; Rom, T.M.; Jauhari, I. Temperature performance and usage conditions of domestic refrigerator-Freezers in Malaysia. Hong Kong Inst. Eng. Trans. 2005, 12, 30-35. [CrossRef]

30. Brennan, M.; Kuznesof, S.; Kendall, H.; Olivier, P.; Ladha, C. Activity Recognition and Temperature Monitoring (ART) Feasibility Study; Unit Report 25, Social Science Research Unit; Food Standards Agency: London, UK, 2013. Available online: https://www.food.gov.uk/science/research/ssres/foodsafetyss/fs244026a (accessed on 18 June 2018). 
31. Khan, M.I.H.; Afroz, H.M. An experimental investigation of door opening effect on household refrigerator; the perspective in Bangladesh. Asian J. Appl. Sci. 2014, 7, 79-87.

32. Brown, T.; Hipps, N.A.; Easteal, S.; Parry, A.; Evans, J.A. Reducing domestic food waste by lowering home refrigerator temperatures. Int. J. Refrig. 2014, 40, 246-253. [CrossRef]

33. Garrido, V.; García-Jalón, I.; Vitlas, A.I. Temperature distribution in Spanish refrigerators and its effect on Listeria monocytogenes growth in sliced ready-to-eat ham. Food Control 2010, 21, 896-901. [CrossRef]

34. Macías-Rodríguez, M.E.; Navarro-Hidalgo, V.; Linares-Morales, J.R.; Olea-Rodríguez, M.A.; Villarruel-López, A.; Castro-Rosas, J.; Gómez-Aldapa, C.A.; Torres-Vitela, M.R. Microbiological safety of domestic refrigerators and the dishcloths used to clean them in Guadalajara, Jalisco, Mexico. J. Food Prot. 2013, 76, 984-990. [CrossRef] [PubMed]

35. Qureshi, B.A.; Zubair, S.M. The impact of fouling on the condenser of a vapor compression refrigeration system: An experimental observation. Int. J. Refrig. 2014, 38, 260-266. [CrossRef]

36. Hermes, C.J.L.; Melo, C. Assessment of the energy performance of household refrigerators via dynamic simulation. Appl. Therm. Eng. 2009, 29, 1153-1165. [CrossRef]

37. Belman-Flores, J.M. Thermal study of the compartments of a domestic refrigerator: Influence of fouling condenser. Revista Latinoamericana de Innovación Tecnológica Ciencia y Sociedad 2016, 1, 11-14. (In Spanish)

38. Lepthien, K. Umweltschonende Nutzung des Kühlgerätes im Privaten Haushalt. Bachelor's Thesis, Rheinische Friedrich-Wilhelms-Universität Bonn, Institut für Landtechnik, Abteilung Haushaltstechnik, Bonn, Germany, 2000.

39. Laguerre, O.; Derens, E.; Palagos, B. Study of domestic refrigerator temperature and analysis of factors affecting temperature: A French survey. Int. J. Refrig. 2002, 25, 653-659. [CrossRef]

40. Aprea, C.; Greco, A.; Maiorino, A. HFOs and their binary mixtures with HFC134a working as drop-in refrigerant in a household refrigerator: Energy analysis and environmental impact assessment. Appl. Therm. Eng. 2018, 141, 226-233. [CrossRef]

41. UNEP. The Kigali Amendment to the Montreal Protocol: HFC Phase-down, Ozon Action Fact Sheet. In Proceedings of the 28th Meeting Parties to Montreal Protocol, Kigali, Rwanda, 10-14 October 2016; pp. 1-7.

(C) 2019 by the authors. Licensee MDPI, Basel, Switzerland. This article is an open access article distributed under the terms and conditions of the Creative Commons Attribution (CC BY) license (http:/ / creativecommons.org/licenses/by/4.0/). 